\title{
Drunk and Drive Detection using Raspberry Pi
}

\author{
A. Siri Pallavi', K. Varun Kumar ${ }^{1}$, T. Vamsi Krishna' ${ }^{1}$, S. Sandeep ${ }^{2}$, T. S. Jyothi Lakshmi ${ }^{3}$ \\ 1B.Tech, ${ }^{2}$ Assistant Professor, ${ }^{3}$ Associate Professor \\ 1,2,3 Department of E. C. E, Engineering \& Technology Program, Gayatri Vidya Parishad \\ 1,2,3College for Degree \& P.G Courses (A), Visakhapatnam, Andhra Pradesh, India
}

\begin{abstract}
How to cite this paper A. Siri Pallavi | K. Varun Kumar | T. Vamsi Krishna | S. Sandeep | T. S. Jyothi Lakshmi "Drunk and Drive Detection using Raspberry Pi" Published in International Journal of Trend in Scientific Research and Development (ijtsrd), ISSN: 2456-6470, Volume-3 | Issue-3, April 2019, pp.16761678, URL: https://www.ijtsrd.c om/papers/ijtsrd23 251.pdf

Copyright (C) 2019 by author(s) and International Journal of Trend in Scientific Research and Development Journal. This is an Open Access article distributed under the terms of the Creative Commons

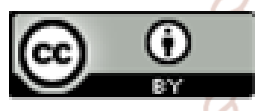
Attribution License (CC BY 4.0) (http://creativecommons.org/license s/by/4.0)
\end{abstract}

\section{ABSTRACT}

In this modern era unnatural deaths are increasing day by day but major part of the unnatural deaths are caused by the drunk driving. Driving while drunk is very dangerous and it leads to vehicle crashes, roadway wounds. Many preventions measures had been taken likewise seizing vehicle permit, fine and punishment, seizing licence. Despite the fact that many prolepsis have been taken still the percentage of accidents due to drunk driving is increasing. This module is proposed to prevent people from unnecessary deaths caused by road accidents due to drunken driving. This module consists of Raspberry Pi model 3, alcohol detection sensor (MQ-3), GPS module and relay to control speed.

\section{INTRODUCTION}

Nowadays, unnatural deaths when taken into consideration major part is due to drunken driving. This module concentrates mainly on drunken driving, according to transport research wing (INDIA) Over 1,37,000 people were killed in road accidents in 2015, that is more than the number of people killed in all our wars put together. Drunken driving is one of the leading causes of road fatalities. Drinking affects driving by decreasing attention and alertness, slow reaction and impaired coordination. In a bid to make Indian road safer and give law a teeth this module decreases unnatural deaths.

Street wellbeing has turned into a noteworthy general wellbeing concern. About 1.25 million individuals kick the bucket in street crashes every year, by and large 3,287 passings per day. An extra 20-50 million are harmed or handicapped. Presently days, numerous street mishaps are happening because of the liquor utilization of the individual who is driving the vehicle. In this manner, smashed driving is most regular reason of mishaps in practically all nations everywhere throughout the world. This proposed framework Drunk and Drive Detection utilizing Raspberry pi is chiefly used to recognize the inebriated drivers and control their vehicles to diminish the mishaps. This framework ought to be introduced in the vehicle. In the event that the individual is tanked and driving the vehicle, at

that point liquor sensor present inside the vehicle recognizes the liquor through the breath of the driver. In the event that the liquor is identified while the vehicle is in running state, at that point speed of the vehicle is diminished to the negligible speed lessens the danger of mishaps.

\section{RELATED WORK}

In [1] This framework is intended to identify the liquor level in the body of the individual who is driving vehicle and maintain a strategic distance from mishaps happening because of alcoholic and driving. The proposed framework will distinguish whether the individual who is driving vehicle is tanked or not and we are going to control the vehicle. This should be possible utilizing raspberry pi. In the event that the individual is smashed methods vehicle is naturally backed off.

In [2] MQ-3 liquor sensor is set over the controlling so that at whatever point the driver breathes out through his mouth the sensor computes the liquor level in his breath. After the motor is touched off in the event that the liquor content is in the scope of $0.02-0.03 \%$, at that point the greatest speed of the vehicle diminishes to $30 \mathrm{Km} / \mathrm{H}$.

In [3] A start framework which will deliver flash attachments is develop as a model to act like the start starter over the 
vehicle's motor. The start framework will work dependent on the dimension of blood liquor content (BAC) from human breaths identified by liquor sensor.The principle reason behind this undertaking is "Tanked driving discovery". Presently a days, numerous mishaps are happening in light of the liquor utilization of the driver or the individual who is driving the vehicle.

\section{SYSTEM MODEL}

Drunk driving is the reason behind most of the deaths, so the Drunk Driving Detection with Car Ignition Locking Using Raspberry $\mathrm{Pi}$ aims to change that with automated, transparent, non-invasive alcohol safety check in vehicles. The system uses raspberry pi with alcohol sensor and dc motor, achieve this purpose. System uses alcohol sensor, raspberry pi with dc motor to demonstrate as vehicle engine. System constantly monitors the sensitivity of alcohol sensor for drunk driver detection. If driver is drunk, the processor instantly stops the system ignition by stopping the motor. If alcohol sensor is not giving high alcohol intensity signals, system lets engine run. At the same time, it is connected to a network from where the person who is driving is being monitored.

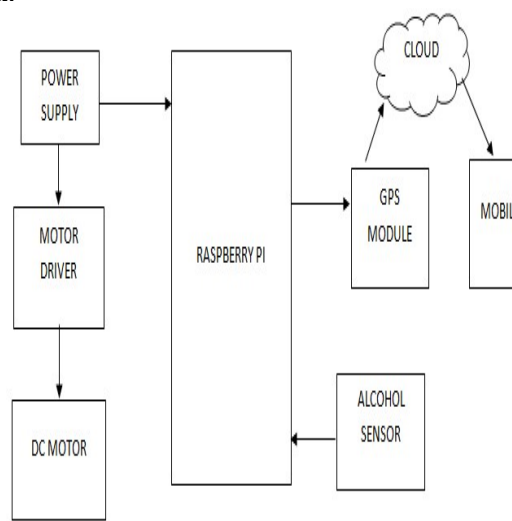

Fig. 1. Design of system

The raspberry pi processor constantly processes the alcohol sensor data to check drunk driving and operates the speed control of the vehicle accordingly. The speed of the vehicle is reduced to the minimal speed so that the possibility of occurring of accidents can be reduced. At the same time, it is connected to a network from where the person who is driving is being monitored. An alert push notification is sent to the registered user.

\section{EXPERIMENTAL SETUP}

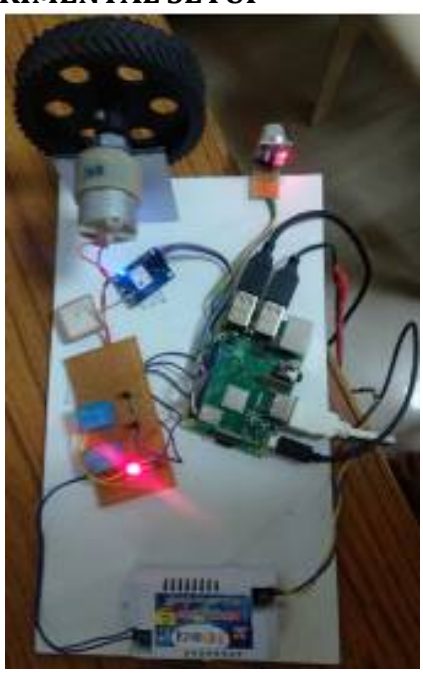

Fig. 2. Experimental Setup
Whenever the person starts the vehicle then the system starts working. Here switch is connected to GPIO 23 which resembles car ignition. Check the alcohol level using alcohol sensor. MQ-3 sensor has 4 pins VCC, GND, D0 and A0. If alcohol does not get detected, then the sensor delivers digital bit 1 through D0 to raspberry pi GPIO pin 17. There are two relays named voltage relay (1) and on and off switch relay (2) connected to raspberry pi via GPIO 27 and GPIO 22. Two BC $547 \mathrm{~N}-\mathrm{P}-\mathrm{N}$ transistors are used as switch between raspberry pi and relays. Relay has 4 pins two for switching purpose between voltages and the other is for input supply from $12 \mathrm{~V}$ battery and the last one is for GND which is connected to emitter of N-P-N transistor. When alcohol does not get detected then voltage relay which is connected to $12 \mathrm{~V}$ battery and raspberry pi GPIO 27 delivers $12 \mathrm{~V}$ which further connected to switch relay (2) is in open circuit type when $12 \mathrm{~V}$ is delivered to it then the switch is thrown to ON state. The relay (2) also delivers $12 \mathrm{~V}$ as output to the motor. The motor starts i.e. the motor resembling car engine gets started.

At the initial checking condition i.e. before starting the car if alcohol gets detected then MQ-3 sensors delivers digital bit 0 to raspberry pi then the car ignition gets locked and here the motor driver does not get any voltage and stops working. Here, GPS activated which is connected to the raspberry pi sends the latitude and longitude values to the registered number. GPS TX pin is connected to RX GPIO pin of the raspberry pi and RX pin of the GPS is connected to the TX GPIO pin of the raspberry pi.

Here MQ-3 sensor has in built potentiometer where it works as threshold level for the sensor. MQ-3 sensor converts the PPM value to analog value and operates by comparator logic. The potentiometer value is connected to second pin of the comparator where it acts as reference value for the sensor. When the PPM value crosses the reference, voltage set by potentiometer then comparator gets output as 1 which shows alcohol is sensed by the sensor or else the output is zero where no alcohol is detected by the sensor.

\section{CASE-2}

Here in this case if the alcohol gets detected during driving till the moment the alcohol gets detected relay delivers the $12 \mathrm{~V}$ to the motor and hence car is driven without any restrictions. The moment when it gets detected during driving the alcohol sensor sends digital bit 1 to the raspberry pi through D0. The raspberry which is connected to relay (2) through GPIO pin 22 reduces the speed through relay. Relay (1) is been connected to voltage regulator $\operatorname{lm} 7809$. Here the input of voltage regulator is connected to $12 \mathrm{~V}$ battery and the output is connected to relay (1) where it now receives $9 \mathrm{~V}$ as already relay (2) is switched on i.e. car is in running state.

Now, relay (2) receives $9 \mathrm{~V}$ where the output of relay(2) is connected to motor slows down at a rate of $50 \%$ speed. When car speed is reduced to $50 \%$ after the detection of alcohol then GPS latitude and longitude values are sent to the registered number. After detecting alcohol during motion, the car continues to move slowly. Hence car can be tracked, stopped and reduce the consequences. 


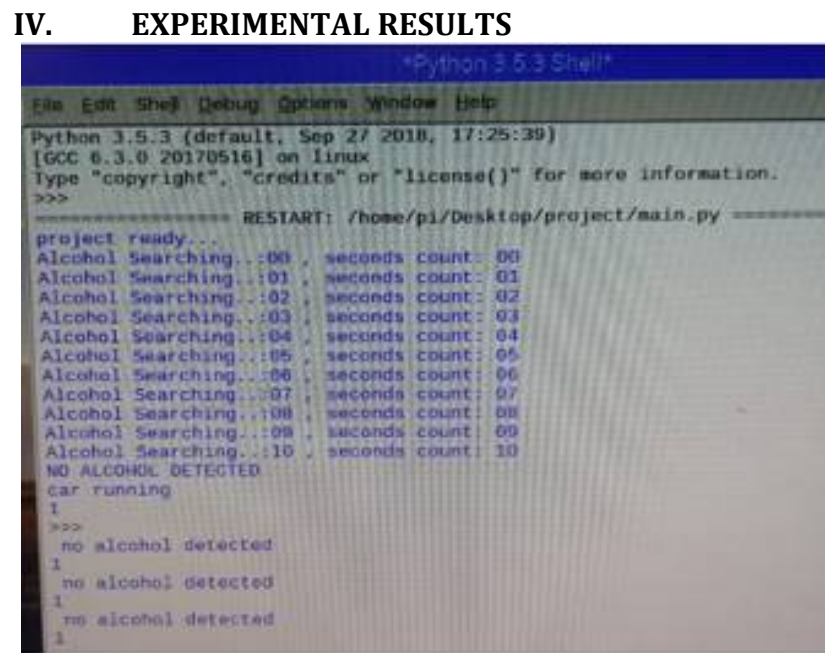

Fig.3. Initial output

The above mentioned figure depicts initial stage when the driver starts the car, MQ-3 sensor detects alcohol percentage and sends the digital output to the raspberry-pi. In the other way around if there is no alcohol detected then vehicle ignition starts.

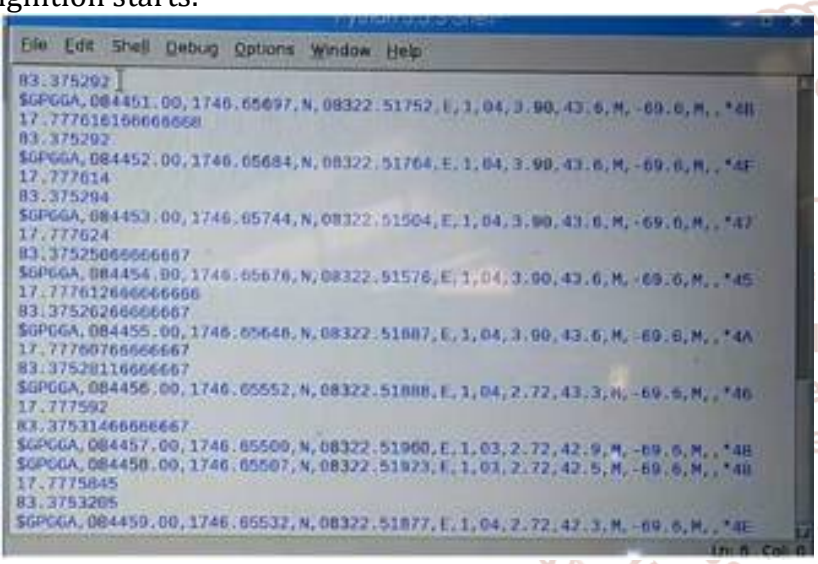

Fig.4. Latitude and Longitude values

When the sensor detects the alcohol then ignition gets locked and the location (latitude and longitude value) of the vehicle is sent to the registered mobile number. As the below figure illustrates the sms thread.

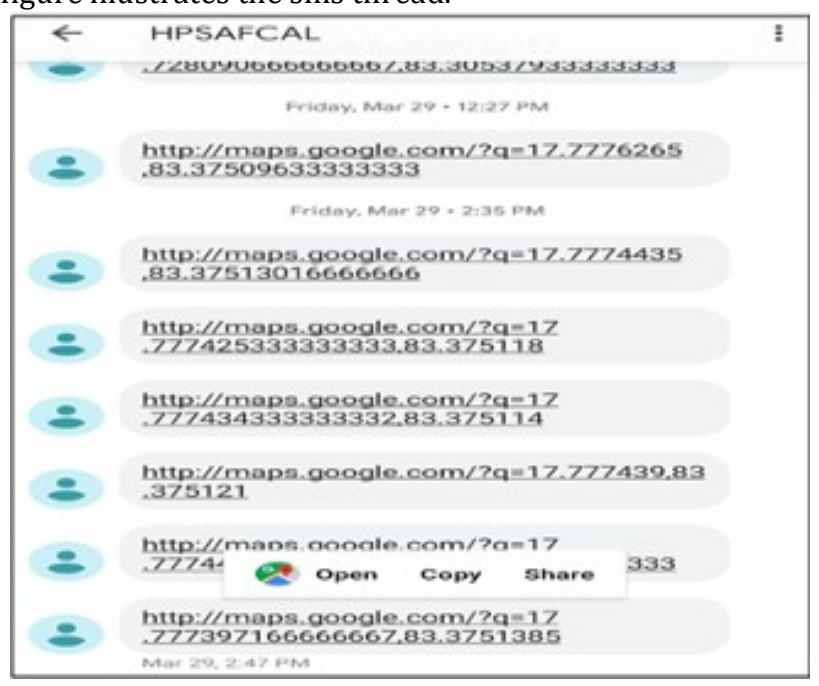

Fig.5. Notification thread

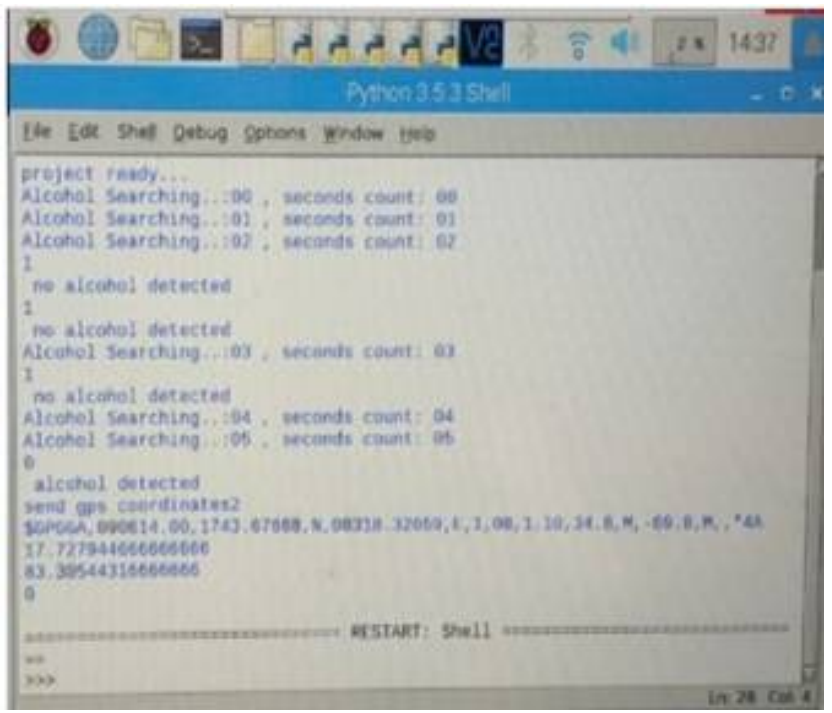

Fig.6. Final Output

When the vehicle is in motion, if MQ-3 sensor detects alcohol the speed of the vehicle will be attenuated and comes to a ideal state. The above output signifies the proclaimed theory.

\section{CONCLUSION}

Driving mishaps are one of the serious issues now a days. This model gives multi arrange testing such a way, that we can evade mishaps brought about by drunken driving. Along these lines, proposed framework can lessen the quantity of street mishaps that are happening because of smashed driving. This framework needs to actualize in vehicles or any four wheelers. In future it very well may be actualized in bikes too. It can likewise be utilized in any association to distinguish intoxicated people. Notwithstanding this GPS module can likewise be utilized to recognize the area of vehicle if liquor content is found in the body. By Using the GPS module, we can consistently the track the vehicle area.

\section{REFERENCE}

[1]. Supraja, Bhanu Sri, Mary Posonia "DRUNK AND DRIVE DETECTION USING IOT" International Journal of Pure and Applied Mathematics, Volume 118 No. 202018

[2]. T. Venkat Narayana Rao, Karttik Reddy Yellu. "Preventing Drunken Driving Accidents using IOT" International Journal of Advanced Research in Computer Science, Volume 8, No. 3, March - April 2017

[3]. Vaishnavi. M, Umadevi.V, Vinothini. M, Bhaskar Rao . Y , Pavithra. S “Intelligent Alcohol Detection System For Car" International Journal of Scientific \& Engineering Research, Volume 5, Issue 11, November-2017. 